\title{
Karolina Borońska-Hryniewiecka
}

\section{LEGITIMACY THROUGH SUBSIDIARITY? THE PARLIAMENTARY CONTROL OF EU POLICY-MAKING}

\author{
DOI: $10.1515 / p p s r-2015-0006$
}

\begin{abstract}
This article explains the relationship between subsidiarity and legitimacy of policies designed at EU level. Through means of theoretically informed analysis this paper claims that if the principle of subsidiarity is respected and implemented throughout the policy process, EU policy-making can aspire to satisfy the condition of both input and output legitimacy. The empirical part of the paper shows how, through a subsidiarity control mechanism known as the Early Warning System, national parliaments can collectively fulfill representative and deliberative functions in EU policymaking. Conclusions about the changing dynamics in parliamentary modus operandi in the field of EU affairs lead to forming a set of recommendations for further research.
\end{abstract}

Keywords: subsidiarity, legitimacy, European Union, policy-making, parliaments

\section{Introduction}

Legitimacy is an important aspect of public policy and governance. Usually, when we think about legitimacy, we imply the democratic nature of a political regime (government). Yet, legitimacy also refers to policy content and this aspect has to date received relatively little attention. Each year, an increased number of policies and regulations implemented at national level originate from the European Union (EU) (compare: House of Commons 2010). For this reason, and in the context of the persisting financial and economic crisis, the legitimacy of EU policies and polity is becoming an issue of growing political salience. On the other hand, the principles of "good governance" enshrined in the European Commission's White Paper on European Governance (2001) such as openness, transparency, participation, accountability, effectiveness and subsidiarity are becoming objects of public questioning and academic debate.

This article focuses on the last of these principles: subsidiarity. Its aim is to elucidate the relationship between subsidiarity and the legitimacy of policies designed at EU level. Through means of theoretically informed and empirically grounded analysis this paper claims that if the principle of subsidiarity is respected and implemented throughout the policy process, EU policy-making can aspire to satisfy the condition of both input and output legitimacy.

The paper starts with a conceptualisation of two kinds of legitimacy in the context of EU governance. It then introduces the concept of subsidiarity linking its scope and 
application within the common framework of legitimacy arguments. Finally, it focuses on the provisions of the Lisbon Treaty and the practical application of the principle by national and regional parliaments. It shows how, through a subsidiarity control mechanism, parliaments can collectively fulfill representative and deliberative functions in EU policymaking. The paper closes with conclusions and their implications for further research.

\section{Two dimensions of legitimacy in the context of EU policy-making}

Fritz Scharpf, a prominent scholar of public policy and European integration, distinguished between two understandings of the concept of legitimacy using the labels of input and output. According to Scharpf, input oriented legitimacy pre-supposes that in a democratic polity, the powers of government must be exercised in response to the articulated preferences of the governed: which, in the language of Abraham Lincoln refers to "government by the people" $(1999,6)$. In modern political systems, this function is usually exercised by parliaments as legitimate and directly elected representatives of the people. On the other hand, output oriented legitimacy demands that democratic government should advance the common good by dealing effectively with such problems that are beyond the reach of individual's to act upon, market exchanges and voluntary cooperation amongst individuals and groups in civil society: which, in Lincoln's terms emphasises the dimension of "government for the people" $(1999,11)$. In other words: while the input argument refers to the character of policy process as ensuring adequate representation and participation for the interested parties in the process of decision-making (inclusive governance), the output argument refers to the effectiveness of policy outcomes understood as satisfying the social and economic needs of the society (effective governance). Nowadays, the erosion of political trust facing public institutions and the modern state means that policy-makers no longer can rely only on legitimacy capital of the polity (regime) itself as inducing sufficient support for every political decision made, but must make sure that public policies are able to stand on their own and be justifiable by their content, scope and effects (compare: Hanberger 2004).

The creation of a supranational policy framework for the European Union, where the preconditions for democratic accountability are not fully realised, has challenged the input dimension of legitimacy. On the other hand, the recent economic and financial crises have uncovered weaknesses in the output side of European governance, not only in its fiscal and monetary sphere (Scharpf 2011; Moravcsik 2012), but also in the way EU policies are designed and implemented. The reasons for this twofold legitimacy deficit are several. Firstly, delegation of power and policy tasks from member states to a supranational agency (European Commission), where a multitude of specialised agendas and departments decide what is best for European citizens, has resulted in a blurring of political responsibility for policy outcomes. While at the national level, government is held accountable for its decisions and can be "punished" by voters in the subsequent elections, at EU level, citizens find it hard to locate the main decision-makers, let alone sanction their actions. Secondly, European integration has caused an increase in executive power and a decrease in national parliamentary control, which has often been referred to as de-parliamentarisation of EU governance structure (O'Brennan and Raunio 2007). 
EU level decision-making is dominated by executive actors: national ministers in the Council of Ministers and European Council, as well as government appointees in the Commission. The European Parliament (EP), though institutionally empowered after the Lisbon Treaty, is still weak in terms of its democratic representativeness and political leverage. EU citizens do not identify with European parties and EP elections are thought to be 'second-order' (Reif and Schmitt 1980; Kousser 2004). Finally, EU technocratic decisions based on market calculations produce a "policy drift" away from voters' policy preferences (Follesdal and Hix 2006). Due to its neo-liberal regulatory character and mainly economic orientation, the EU adopts many policies that are, especially in the context of the current economic crisis, not supported by the majority of citizens in many Member States. ${ }^{1}$ As Weiler aptly put it, Europe is suddenly seen (...) as an emblem of austerity (2012) which dramatically diminishes public trust in EU institutions. ${ }^{2}$ On the other hand some national governments are able to undertake policies at European level that they cannot pursue at domestic level, where they are constrained by parliamentary opposition, courts or corporatist interest groups, with such states of affair evoking social unrest. An illustration of such states of affair was the recent bout of European protests against the ACTA agreement elaborated in anonymous technocratic circles of governments and corporations, or demonstrations against austerity measures resulting from the adoption of the Fiscal Pact.

\section{Subsidiarity as a remedy for EU legitimacy deficit?}

One of the main promises of the Lisbon Treaty was to increase the democratic legitimacy of the EU through, inter alia, enhancing and extending the principle of subsidiarity. While the enhancement meant equipping national parliaments with effective tools for controlling the compliance of EU policy-making with the principle of subsidiarity, the extension referred to including, for the first time, regional (sub-national) legislative chambers into the very process. Taking into account that few legal or political concepts in the European acquis communautaire have provoked such a degree of controversy and also interest as subsidiarity has. Its conceptualisation will be addressed below.

\section{The conceptual challenge of the principle of subsidiarity}

The principle of subsidiarity links the input and output dimensions of legitimacy inasmuch as it regulates the allocation and the use of authority within a political decision-making process according to democracy- and efficiency- related arguments. Normatively, it reflects the democratic ideal that policy process should be controlled by those affected by it to ensure that policies and laws reflect the interests of and respond to the needs of a society.

\footnotetext{
${ }^{1}$ According to the latest figures published in the Guardian (April 2013) public confidence in the EU has fallen to historically low levels in the six largest EU countries, see: http://www.theguardian.com/world/2013/ apr/24/trust-eu-falls-record-low, accessed 25.10.2013.

2 The analysis of Standard Eurobarometers 75-79 covering the years 2010-2013 reveals a gradual decline in public trust in EU institutions oscillating around 30\% in 2013.
} 
Functionally, the principle holds that powers or tasks are to rest with the sub-units of the political system unless a central unit is more effective at achieving certain specified goals.

At EU level, the principle of subsidiarity is enshrined originally in article 5(3) of the Treaty on European Union (TEU) which states that "in areas which do not fall within its exclusive competence, the Union shall act only if, and in so far as the objectives of the proposed action cannot be sufficiently achieved by the Member States, either at central level or at regional and local level, but can rather, by reason of the scale or effects of the proposed action, be better achieved at Union level". As a matter of fact, article 5(3) TEU does not define subsidiarity per se but rather sets a rule when the EU should intervene in order to comply with the principle (on the evolution of the concept in EU treaties see: Duff 1993; on the origin of subsidiarity and its evolution within the case law of the Court of Justice of the EU see: Horsley 2012).

And so, according to article 5(3) TEU two conditions should be fulfilled for EU action to be justified: 1) insufficiency of member states in performing the action at national level (insufficiency test) and 2) added value of the same action performed at EU level (added value test) (See more in: Schütze 2009; Kiiver 2012). These two substantive conditions for the application of the subsidiarity principle require further notice. What kind of evaluations should be employed to assess whether a certain action is in fact "better achieved"? Although words "sufficiently" or "better" might turn out contestable and can be interpreted using different rationales and criteria, it is commonly admitted that in this context the objective which constitutes the fundament and gives sense to the subsidiarity principle is the maximum relative efficacy of the level of governance which acts within the legal framework of the attribution of competences (Popelier and Vandenbruwaene, 2011). In this sense, the principle of subsidiarity encompasses the requirement of rationality and certain moderation in the exercise of competences shared between the EU and member states entailing a twofold logic of conduct: i.e. negative, expressed by the right to say 'no' to the unjustified (inefficient, irrational) EU intervention leading to unnecessary centralisation of policy-making; and positive, according to which the EU should act to help the member states when they are not capable of achieving the desired results by intervention at national level. Taking the above into account, we could then define subsidiarity as a principle determining the level of governance at which particular policy should be exercised considering the relative efficiency of action and its proximity to citizens.

The practical application of the subsidiarity provision as stated in article 5(3) TEU requires taking two kinds of concern into consideration: political (also called material) and legal (procedural). With respect to the first, the two already discussed conditions of insufficiency and added value should be satisfied by the legislators. In other words, the EU action must be necessary, should bring added value over and above what could be achieved by a Member States actions alone, and with the former two being satisfied, the decisions should be taken as closely as possible to the citizen in accordance with the general commitment of EU legislators included in the Preamble of the Lisbon Treaty. In this sense, subsidiarity has a considerable normative appeal in representing a "good" and "just" rule of governance (Burrows et al., 2004). Yet, deciding whose action (EU or member state) will be more efficient, beneficial and thus legitimately entailing an eminently 
political interpretation and at the same time, a certain degree of discretionality. From this point of view, the final decision about the legitimisation of policy intervention at the best suited level of governance is rather an outcome of politically and economically grounded arguments rather than absolutely objective evaluation (Compare: Palomares Amat, 2011).

As regards the legal aspect of subsidiarity, we refer to certain procedural requirements which EU legislators need to fulfill before presenting legislative drafts and which can later become subject to the judicial control of the EU Court of Justice (For the role of the Court in subsidiarity control see Horsley, 2012). Here, the object of control can be threefold. Firstly, the correct exercise of competences has to be observed. It is clear that subsidiarity applies in the sphere of non-exclusive powers, i.e. competences shared between the EU and member states. ${ }^{3}$ Secondly, the legislator needs to include in the draft legislative proposal a justification of the planned action with regards to the subsidiarity principle, but also in the form of a comprehensive impact assessment of the proposed legislative measures [art. 5 of Protocol no. 2 on the application of the principles of subsidiarity and proportionality attached to the Lisbon Treaty (hereafter Protocol no. 2)]. Through such assessment the Commission evaluates the potential economic, social and environmental consequences of its future legislation, as well as those regarding the regulatory burden for the private and public sectors, which is also part of the Commission's commitment for Better Regulation [See: $\operatorname{COM(2009)} 15$ final]. In this respect, it should be noted that Protocol no. 2 also mentions another principle which should be observed by EU legislators, namely, the principle of proportionality according to which "the content and form of EU action shall not exceed what is necessary to achieve the objectives of the Treaties" [art. 5(4) TEU]. Thirdly, the judicial control can also extend to the sphere of specific pre-legislative requirements imposed on the legislator by the Lisbon Treaty such as the obligatory consultations with particular stakeholders, including regional and local authorities (i.e. Committees of the Regions) or representatives of the civil society and social partners (i.e. the European Social and Economic Committee) (Implicit in art. 2 of Protocol no. 2; explicit in art. 307 TEU).

\section{Subsidiarity control provisions in the Lisbon Treaty}

The most important institutional provision related to the control of the principle of subsidiarity is undoubtedly the parliamentary mechanism of subsidiarity scrutiny known as the Early Warning System (hereafter EWS). Within its framework, national parliaments have eight weeks from the date of the transmission of an EU draft legislative act to analyse it and issue a reasoned opinion if they consider that the draft in question does not comply with the principle of subsidiarity (art. 6 of Protocol no. 2). Two procedures can emerge from this process:

"Yellow card": when at least one third of national parliaments (one vote per chamber in bicameral systems) oppose the draft legislative act on the basis

\footnotetext{
${ }^{3}$ Shared competences between the Union and member states occupy the broadest category of policy fields in the Lisbon Treaty. These include: internal market; economic, social and territorial cohesion; social policy; agriculture and fisheries; environment; consumer protection; transport; pan-European networks; energy; area of freedom, security and justice; joint security issues with regard to aspects of public health; research, technological development and space; development cooperation and humanitarian aid.
} 
of its non-compliance with the subsidiarity principle, the initiator of the contested draft must review the proposal. He may then decide to maintain, amend or withdraw the draft, however reasons must be given for each decision in a form of Communication [art. 7(2) of Protocol no. 2]

"Orange card" (applying only to EU draft legislative acts under the ordinary legislative procedure): when more than half of the national parliaments oppose such an act on grounds of subsidiarity breach the latter must be reviewed. The European Commission may then decide to maintain, amend or withdraw the proposal. If the Commission decides to maintain it, it has to provide a reasoned opinion justifying why it considers the proposal to be in compliance with the subsidiarity principle. On the basis of this reasoned opinion and that of the national parliaments, the European legislator (by a majority of 55 per cent of the members of the Council or a majority of the votes cast in the European Parliament) shall decide whether or not to block the Commission's proposal. If either of them shares the opinion of the national parliaments about the subsidiarity breach the legislative proposal will not proceed [art. 7(2) of the Protocol no. 2]

Although national parliaments have not obtained the possibility to use the "red card" (i.e. to veto EU legislative projects), article 8 of Protocol no. 2 grants them the right to bring legal action before the CJEU on the basis of subsidiarity breach provided that they had previously issued a reasoned opinion within the EWS. In addition, what constitutes novelty in the context of EU multilevel governance, article 6 of Protocol no. 2 recognises regional parliaments with legislative powers as a separate category of institutions involved in the EWS by stating: "it will be for each national Parliament or each chamber of a national Parliament to consult, where appropriate, regional parliaments with legislative powers". Although such provision leaves much scope for interpretation of the actual role that regional parliaments should play in the control of the EU legislative process, it unequivocally recognises the possibility of them being consulted in the subsidiarity review, thus opening yet another channel of democratic participation, and thus legitimisation, in EU policy-making.

\section{National parliaments and subsidiarity control}

Although parliamentary contribution to EU policy control had already started before the coming into force of the Lisbon Treaty, within the so called Political Dialogue, the introduction of the EWS granted the process legal leverage through the system of sanctions for EU legislators (i.e. yellow or orange cards). Moreover, it established an additional, next to the EP, formal link between the citizens and the Commission providing an extra legitimacy channel in the EU system of political representation.

\footnotetext{
${ }^{4}$ Under Political Dialogue (known also as the 'Barroso Initiative') the Commission transmits all new proposals and consultation papers directly to national parliaments and invites them to give comments, criticism and positive feedback regarding their content. Within the scope of the PD, parliaments can assess the compliance with the principles of subsidiarity, proportionality, conferral and political accountability. Although the character of the PD is informal and non-binding for the Commission, it usually takes notice of their comments. It can be said that the EWS is the 'hard core' of the broader PD.
} 
Operationalisation of the EWS provisions required national parliaments to undertake a range of activities aimed at adapting their own administrative structures towards exercising the new competences. The changes included both the intra-, as well as interparliamentary dimensions of their activities. Regarding the first, parliaments had to organise themselves in terms of resources such as expertise and personnel to meet the eight-week deadline for the submission of a reasoned opinion. In relation to the second, the effective exercise of the EWS entailed establishing effective coordination systems with parliaments of other member states as to the scope and methodology of the subsidiarity scrutiny (for a detailed overview of the EWS see: Kiiver 2012).

The first year of using the procedure revealed weaknesses in the system as only 59\% of the scrutiny processes initiated were completed on time (Kaczyński 2011). Moreover, the under-provision of adequate communication and cooperation mechanisms among national parliaments hindered the effective articulation of common opinions. The operating procedures showed that effective subsidiarity control (resulting in the review of draft legislative acts by the Commission) can only be applied collectively via synergy rather than as individual input. ${ }^{5}$ Until the collective voice at national level is organised effectively, the reasoned opinions of single parliaments, although acknowledged by the Commission, are of little relevance in the EU legislative process.

The two following years (2011-2012) witnessed an increase in the number of reasoned opinions sent to the Commission. In 2011, the Commission received 64 opinions from national parliaments, which marks an increase of almost 75\% in comparison with 2010 (COM/2012/373). According to the IPEX database, in 2012 the Commission received 88 reasoned opinions. ${ }^{6}$ The five most participative chambers were the Swedish Riksdag, the Luxembourg Chambre des Députés, the Polish Sejm and Senat and the UK House of Commons. ${ }^{7}$ More importantly, in 2012, the first threshold for a "yellow card" was reached regarding the Commission's proposal for a Council regulation "On the exercise of the right to take collective action within the context of the freedom of establishment and the freedom to provide services" (COM/2012/130 final) known also as "Monti II regulation". The aim of the proposal was to develop a legislative framework for regulation of transnational industrial action (the right to strike) in the context of the EU internal market (free movement). However, it met with strong opposition among trade unions and employers. Reasoned opinions were delivered by 12 national chambers representing 19 votes under the EWS ${ }^{8}$. The main arguments against the regulation were lack of clarity as to its purpose;

${ }^{5}$ However, the EWS also provides parliaments with an individual power, that cannot be underestimated, in the sense that, by way of the EWS, each national parliament can act autonomously from its executive and express its views (sometimes differing from the government) representing national public opinions directly to the EU institutions.

${ }^{6}$ IPEX is an inter-parliamentary EU information exchange: http://www.ipex.eu/IPEXL-WEB/home/ home.do, accessed 17.06.13

7 See IPEX database.

8 Reasoned opinions were issued by 12 unicameral parliaments (Danish, Swedish, Swedish, Lithuanian, Portuguese, Luxembourgian and Maltese) as well as the Polish Sejm, French Senate, Belgian House of Representatives, UK House of Commons and the States General of the Netherlands. 
lack of EU competence over industrial relations; and its potential incompatibility with the well-functioning national arrangements in the area of labour law (compare: Niklas Bruun and Andreas Bücker 2012).

This first effective use of the yellow card deserves special attention since the nature of this particular parliamentary scrutiny has raised certain questions. Although, according to the Commission, the reasoned opinions of national parliaments did not address the material and procedural aspects of the principle of subsidiarity ${ }^{9}$, the Commission took notice of their position and decided to withdraw the proposal. At the same time it justified this decision by pointing to insufficient support for the measure on the side of national governments (in the EU Council). ${ }^{10}$ It is important to notice that the proposal was objected mainly by countries where industrial relations and high standards of social dialogue play important roles in domestic politics. This decision should also be viewed in the context of the current economic crisis where its governance has been characterised by a lack of social policy consideration. The EU imposed austerity measures (i.e. cuts in social benefits, wages, employment reductions) affect mainly the European workforce. In the eyes of those opposing "Monti II regulation", enforcing it, the EU would commit another above-mentioned "policy drift" away from EU citizens and further undermine its output legitimacy. In this sense, although not explicitly mentioned in the reasoned opinions, the subsidiarity argument worked well, showing that decisions regarding labour issues should be either left to national considerations which are more responsive to the specific models of industrial relations, or elaborated more carefully at EU level (for a different view see: Fabbrini and Granat 2013). Moreover, broader interpretation of subsidiarity by national parliaments is explained by the fact that its application depends in great part on political evaluation which is inherent in the nature of parliamentary institutions performing the scrutiny under the EWS. Parliaments as political actors are created to foster public deliberation on policy proposals and not to asses them in strictly legal terms as if they were courts. In this sense, the successful activation of the first yellow card in the subsidiarity control mechanism can be viewed as a precedent which might have further positive consequences for parliamentary involvement in European policy-making.

\section{Regional parliaments ${ }^{11}$ in subsidiarity control}

One of the main novelties of the Lisbon Treaty in terms of enhancing EU legitimacy is the extension of the application of the principle of subsidiarity to the regional level [art. 5(3) TEU]. In doing this, the EU has imposed on itself the obligation to respect

9 The analysis of the reasoned opinions show that national parliaments have expressed reservations to the choice of a wrong legal basis and the breach of the principle of proportionality as main weaknesses of the proposed regulation. For more see: Fabbrini and Granat 2013.

${ }_{10}$ See the letter by President Barroso to the President of the European Parliament, Mr Martin Schulz, Memo 12/661, 12 September 2012.

11 There are currently 74 sub-national parliaments in the EU, which exercise constitutionally attributed law-making competences in various fields of policy. They can be found in eight EU member states: three federal (Austria, Belgium and Germany), two regionalised (Spain and Italy), one devolved (the UK) and two unitary states (Portugal-Madeira and Azores; and Finland-Åland Islands). The legislative capacity varies from one Member State to another. 
the degree of regional autonomy of EU Member States through, inter alia, taking into account the legislative competences of regional authorities while drafting EU policies. In this sense, article 4 (2) TEU specifies that the EU "shall respect (...) national identities, inherent in their fundamental structures, political and constitutional, inclusive of regional and local self-government". The treaty, ipso facto, institutionalises for the first time, the regional tier of jurisdiction as a distinct element of the EU system of multilevel governance. In the same vein, the Commission is expected to extend its pre-legislative consultations and impact assessments to regional and local level (respectively art. 2 and 5 of Protocol no. 2). The dialogue which takes place between the Commission and the regional stakeholders prior to the presentation of legislative proposals takes several forms, such as mandatory consultation with the Committee of the Regions on key policy areas of regional concern, sectoral consultation on the specific conditions for EU intervention in various policy fields or the structured dialogue with associations representing regional interests.

The extension of the principle of subsidiarity to the regional level seems not only justified, but also desirable; most of all for legitimacy-related reasons (Weatherill, 2005; Popelier and Vandenbruwaene, 2011). From the output legitimacy point of view, it must be remembered that regional and local authorities implement over $70 \%$ of EU legislation (Christiansen and Lintner, 2005). In this respect, their legislative, administrative and fiscal capacities in dealing with specific policies are crucial in conducting subsidiarity and policy impact analyses to estimate the territorial effects of European legislation. The increased capacity of regional authorities in influencing EU policy-making through their involvement in the decision-making process should ideally translate into co-responsibility for governance, awareness of its costs and increase in its effectiveness (Borońska-Hryniewiecka, 2013c).12

Next to efficiency-related arguments, the inclusion of the regional level into the EWS should also be considered as an enhancement of EU input-oriented legitimacy. Regional parliaments are legitimate and directly-elected institutions representing the "multiple demoi" of the EU (compare: Nicolaidis 2003; Benz 2011) and equally contribute to the democratic legitimacy of the EU (Compare Bursens et al. 2012). The Special Eurobarometer (307/2009) reveals that while only one third of Europeans tend to trust their national governments (34\%), half of the citizens express trust towards their regional and local authorities (50\%). The same survey also shows that a large majority of Europeans feel that public authorities at the regional level are not sufficiently taken into account in EU policy-making (59\%). These findings imply that EU citizens not only entrust regional parliaments with a significant scope of political responsibility, but they also expect regional responsiveness to the possibility of being consulted on EU related issues. In this

${ }^{12}$ It is commonly admitted that one of the reasons behind the failure of the Lisbon Strategy was the fact that it was too much of a top-down strategy with ambitious but quite abstract indicators imposed by Brussels and objectives lacking joint frameworks for implementation feeding on the potential of the various territorial levels of government and non-state actors. (Compare: After Lisbon - the role of regional and local authorities in the new Strategy for Sustainable Growth and Better Jobs, A study commissioned by the Committee of the Regions and written by Metis $\mathrm{GmbH}$ on the basis of interviews conducted among by the Lisbon Monitoring Platform on the CoR in 2010). 
case, the inclusion of regional parliaments as the local representative institutions into the scrutiny of EU legislation affecting sub-national competences, links political decisions at supranational level with citizens' preferences on the ground. Finally, the involvement of regional assemblies in subsidiarity control could become a useful way of accelerating the Europeanisation process of sub-national political elites, bridging the gap between regional politics and EU policies (Bauer ET AL., 2010) which, in the long run, could help overcome the long-lasting 'deparliamentarisation' at the sub-national level.

The conducted empirical analysis reveals that since the introduction of the EWS regional parliamentary activity in the sphere of EU affairs has increased. The questionnaires conducted in Italy, Spain, Germany, Austria, Finland, the UK and Belgium reveal that formal inclusion of regional parliaments into the domestic scrutiny process has taken place, albeit in differing ways, and new patterns of interactions between the central and sub-national authorities are being established (for more see: Borońska-Hryniewiecka, 2013a; b). Moreover, there is a general agreement among the majority of the representatives of regional parliaments that participation in the EWS has a positive spill-over effect through enhancing the Europeanisation process of the sub-national administration and political elites, increasing their knowledge about EU legislation and responsiveness to EU affairs. In their analyses of EU draft legislative acts regional parliaments, similarly to the national chambers, take a broader scope addressing the questions of proportionality and policy substance. In this way their awareness is raised regarding the contents of EU legislation thus enhancing democratic legitimisation and co-responsibility for local policy outcomes. Furthermore, subsidiarity scrutiny is also conducted by the Committee of the Regions, which in 2012 established REGPEX, an electronic database serving as an information exchange platform for regional parliaments and governments in the process of subsidiarity monitoring and impact assessment procedures. Today, the network has gathered over 140 members representing not only regional parliaments, but also local governments and municipal authorities from federal, regionalised and unitary member states. ${ }^{13}$

Summing up, such a multi-level system of subsidiarity control, in spite of its still short experience and the existing weaknesses, creates the first legislative transmission belt in the EU system of compound representation thus enhancing (re-) parliamentarisation of the EU governance structure. With regards to the EWS, some authors have even proclaimed the emergence of a 'virtual third chamber' collectively fulfilling the legislative, representative and deliberative function in the EU (Cooper 2012). ${ }^{14}$ Although such claims might be exaggerated, the exchange of views and cooperation between the Commission, the Member States' parliaments and regional assemblies should ideally, result in the positive-sum legitimacy required to justify policies coming from the EU.

${ }^{13}$ See: https://portal.cor.europa.eu/subsidiarity/Pages/default.aspx, accessed 24.10.2013.

14 For contrasting view see: Pieter De Wilde, Why the Early Warning Mechanism does not Alleviate the Democratic Deficit, OPAL Online Paper no. 6, 2012: 3. 


\section{Conclusion}

The aim of this article was to clarify the relationship between legitimacy and subsidiarity in EU policy-making and to show in which ways the application of the latter can reduce the legitimacy deficit of the EU. The paper has explained that subsidiarity involves considering both the input and output dimension of legitimacy in which both democracyand efficiency- oriented arguments are taken into account. The principle of subsidiarity can then be used as an effective tool guiding EU institutions as to the form, scope and intensity of their actions.

While Scharpf (1999: 12) holds that EU policy-making, due to its regulatory character, can only aspire to satisfy the output dimension of legitimacy, this article has shown that, at least from a formal point of view, the newly established parliamentary system of subsidiarity control also fulfils the input oriented legitimacy requirement throughout the policy-making process. By scrutinising EU legislation national parliaments collectively perform the controlling, deliberative and representative function linking the EU and domestic polities. Moreover, in the new institutional perspective of the Lisbon Treaty regional parliaments have also been granted new competences in the field of subsidiarity monitoring thus becoming an emerging player in the EU "multi-level parliamentary field" (Crum and Fossum 2009). The extent to which regional parliaments are included into the EWS will depend on the internal dynamics of the member states and certain mesolevel factors such as the inter-institutional relations between the involved actors, either in the horizontal or vertical dimension (see: Borońska-Hryniewiecka 2013a). Yet, it can be expected that in general, the inter-parliamentary relations induced by the EWS will create a deliberative space among parliaments and thus indirectly enhance the democratic quality of European governance. Additionally, the potential use of the new tool for bringing cases before the CJEU on the basis of subsidiarity breach might result in a more careful and inclusive elaboration of EU policies before these become legislative drafts. In this sense, strategic interactions between EU institutions, interest groups and the Committee of the Regions or the European Economic and Social Committee are likely to be the main source of an increased policy legitimacy.

While the EWS has certainly created new modus operandi between the Commission, national and regional parliaments, further comparative studies are needed to confront and develop the proposed "legitimacy through subsidiarity" argument. There are two possible ways to conduct research in this field. The first is through a comparative analysis of the inter-institutional dynamics at play in different domestic parliamentary systems. Such perspective will allow detection of possible weaknesses and assess the challenges of interparliamentary relations in the sphere of EU affairs. The applied approach can take into account either national or sub-national levels of analysis, or combine the two by looking at the vertical inter-level parliamentary relations in policy-control in EU decentralised states. The second research strand should focus on particular policy fields to analyse in which ways cooperative, policy-oriented forms of governance are created between parliaments of issue-interested member states. Here too, the perspective can be national, sub-national or link both levels of analysis. The literature still lacks in-depth studies of parliamentary 
engagement in the policy shaping phase, especially in cases of policies with significant social impact such as the environment, sustainable development and labour regulations. A researcher wanting to "test" the input legitimacy of certain policy dossiers should take into account questions pertaining to the absence or presence of adequate consultative procedures and impact assessment analyses as well as the qualitative and quantitative aspects of parliamentary input in their elaborations. It could be expected, that with time and more institutional adjustments in place, more parliamentary input will be channelled upwards to the Commission through the EWS. This also encourages the development of more robust theories regarding the actual and potential impact of the EWS on both parliamentary mobilisation and horizontal inter-parliamentary cooperation in the EU.

\section{References:}

Bauer Michael, Pitschel Diana and Philip Studinger. Governance Preferences of Subnational Administrative Elites in the European Union, Lehrstuhl Politik und Verwaltung, Working Paper Series 2010, Vol. 4.

Benz Arthur. Linking multiple demoi. Inter-parliamentary relations in the EU, Institut für Europäische Verfassungswissenschaften, IEV-Online, 2011/1

Borońska-Hryniewiecka Karolina. [a]. Regional parliaments and subsidiarity after Lisbon: Overcoming the regional blindness?, Democracy and Subsidiarity in the EU. National Parliaments, Regions and Civil Society in the Decision-Making Process, (red.) M. Cartabia, N. Lupo and A. Simoncini, 'Il Mulino - Percorsi', Series of Nova Universitas, 2013, pp. 337-364.

Borońska-Hryniewiecka Karolina. [b]. Subnational parliaments in EU Policy-control. Explaining the variations across Europe. Robert Schuman Working Paper Series, 2013/38.

Borońska-Hryniewiecka Karolina. [c]. The role of regional and local authorities in EU development policies in the perspective of the Committee of the Regions. Multi-level governance revisited in the times of crisis. Studia Regionalne i lokalne 2013, vol 3 (53), pp. 21-38.

Bruun Niklas and Andreas Bücker. European Economic, Employment and Social Policy, Critical assessment of the proposed Monti II regulation - more courage and strength needed to remedy the social imbalances. ETUI Policy Brief, $\mathrm{N}^{\circ} 4 / 2012$.

Burrows Noreen, Carter Caitriona and Scott Andrew. Subsidiarity and the Draft Treaty. Discussion Paper for Sub Rosa 2004. [online].[accessed 19.05.2013] available at: http:// www.scotland.gov.uk/Resource/Doc/1071/0003543.pdf

Bursens, Peter, Maes Frederic and Vileyn Matthias. Playing the Next Level of the Multilevel Parliamentary Game. Let's Add Subnational Parliaments to the Scene, Paper prepared for the Political Studies Association Specialist Group Territorial Politics Biennial Conference, 13 - 14 September 2012 Brussels.

Christiansen Thomas and Pamela Lintner. The CoR after 10 Years. Lessons from the Past and Challenges for the Future. EIPAScope 2005, Vol. 1, pp. 7-13.

Cooper Ian. A "Virtual Third Chamber" for the European Union? National Parliaments after the Treaty of Lisbon, West European Politics 2012, 35/3, pp. 441-465. 
De Wilde Pieter. Why the Early Warning Mechanism does not Alleviate the Democratic Deficit, OPAL Online Paper 2012, no. 6.

Duff Andrew. Subsidiarity within the European Community: a Federal Trust report. 1993.

European Commission. White paper on European governance. 2011.

Fabbrini Federico and Katarzyna Granat. Yellow card, but no foul: The role of the national parliaments under the subsidiarity protocol and the Commission proposal for an EU regulation on the right to strike. Common Market Law Review 2013, Issue 1, pp. 115-143

Follesdal Andreas and Simon Hix. Why There is a Democratic Deficit in the EU: A Response to Majone and Moravcsik. Journal of Common Market Studies 2006, Vol. 44. No. 3, pp. 533-62.

Hanberger Anders. Democratic governance and evaluation. Paper presented at the Sixth EES (European Evaluation Society) Conference in Berlin, September 30-October 2, 2004.

Horsley Thomas. Subsidiarity and the European Court of Justice: Missing Pieces in the Subsidiarity Jigsaw? Journal of Common Market Studies 2012, Vol. 50, Issue 2, pp. $267-$ 282.

House of Commons. How much legislation comes from Europe? Research Paper 10/62, 13 October 2010.

Kaczyński Maciej. Paper tigers or sleeping beauties? National Parliaments in the postLisbon European Political System. CEPS Special Report 2011.

Kiiver Philip. The Early Warning System for the Principle of Subsidiarity: Constitutional Theory and Empirical Reality, 2012, London: Routledge.

Kousser Thad. Retrospective Voting and Strategic Behaviour in European Parliament Elections. Electoral Studies 2004, Vol. 23, No. 1, pp. 1-21

Moravcsik Andrew. Europe after the crisis. How to sustain a Common Currency. 91 Foreign Affairs, 54/2012.

Nicolaïdis Kalypso. Our European Demoï-cracy: Is this Constitution a Third Way for Europe?' in Nikolaides, Kalypso \& Weatherill Stephen. Whose Europe? National Models and the Constitution of the European Union, European Studies at Oxford Series 2003.

O'Brenan John and Tapio Raunio. Deparliamentarisation and European Integration, in (eds.) J. O'Brennan, T. Raunio, National Parliaments within the Enlarged European Union. Abingdon: Routledge, 2007. pp.1-26.

Palomares Amat Miguel. La participación del parlamento de Cataluña en la aplicación y el control del principio de subsidiariedad. Revista de Derecho Comuniatrio Europeo 2011, núm. 38, pp. 19-59.

Popelier Patricia and Werner Vandenbruwaene. The Subsidiarity Mechanism as a Tool for Inter-Level Dialogue in Belgium: On 'Regional Blindness' and Co-operative Flaws. European Constitutional Law Review 2011. Vol 7. pp. 204-228

Raunio Tapio. National Parliaments and European Integration: What we know and what we should know. ARENA - Centre of European Studies Working Paper, University of Oslo, 9/2009.

Reif Karlheinz and Hermann Schmitt. Nine Second-Order National Elections A Conceptual Framework for the Analysis of European Election Results, European Journal of Political Research, 1980, 8:1, 3-44. 
Scharpf Fritz Wilhelm. Governing Europe: effective and democratic? New York: Oxford University Press, 1999. ISBN: 9780198295457

Scharpf Fritz Wilhelm. Monetary Union, Fiscal Crisis and the Preemption of Democracy. LEQS Annual Lecture Papers 2011, No. 36/2011

Weatherill Stephen. The challenge of the regional dimension in the European Union. in: Weatherill, Stephen and Bernitz, Ulf (eds.): The role of regions and sub-national actors in Europe 2005, Oxford: Hart Publishing, pp.1-31.

Weiler Joseph. Europe in crisis-on 'political messianism', 'legitimacy'and the 'rule of law'. Singapore Journal of Legal Studies, December 2012, pp. 248-268. 